\title{
Construction and validation of the life roles self-efficacy scale for young adults in school-to-work transition
}

\author{
Pawel Kot ${ }^{1}$ (D) $\cdot$ Bohdan Roznowski ${ }^{1}$ (D) Bernd-Joachim Ertelt ${ }^{2}$ (D)
}

Accepted: 23 September 2020 / Published online: 4 October 2020

(C) The Author(s) 2020

\begin{abstract}
Self-efficacy is widely regarded as a key factor in shaping one's own career. To date, self-efficacy has usually been measured on a one-dimensional basis without taking into account the interaction between the various social roles involved in career development. The social roles were described by Donald E. Super in his career development theory. Adopting this framework, we provide a questionnaire to simultaneously measure self-efficacy in Super's five described social roles. This work presents the development and validation of a new questionnaire entitled the Life Roles Self-Efficacy Scale (LRSES). The questionnaire has been developed based on a series of surveys: the first survey $(N=347)$ aimed to establish the exploratory factor analysis (EFA) and basic psychometric properties of the tool; the second survey $(N=494)$ aimed to verify the confirmatory factor analysis of the method (CFA) and reliability parameters with regard to a new sample; and the third survey $(N=109)$ explored the consistency of results over time. Statistical analysis confirmed this tool to be accurate for assessing one's self-efficacy in school-to-work transitions.
\end{abstract}

Keywords Life roles $\cdot$ Self-efficacy $\cdot$ School-to-work transition

\section{Introduction}

Current research in occupational psychology is focused on the phenomenon of career transitions after completion of one's education (Briscoe, Briscoe et al. 2012; Schlossberg 1996). This literature (e.g., Savickas 2013; Super 1990; Taber and Blankemeyer 2015) has identified three types of career transition: entering the labor market, mid-career crisis, and retirement. Many individuals seek professional support during each of these career stages. In our article, we therefore focus on a new method that could provide counselors a greater understanding of individuals who must make informed career decisions at key transition periods.

Electronic supplementary material The online version of this article (https://doi.org/10.1007/s12144-020-01083-7) contains supplementary material, which is available to authorized users.

Pawel Kot

kotpawel@o2.pl

1 Institute of Psychology, The John Paul II Catholic University of Lublin, Al. Racławickie 14, 20-950 Lublin, Poland

2 School of Social Sciences, University of Mannheim, 11 Burgunderstraße, D-67159 Friedelsheim, Germany
As a consequence of its immense importance to the course of an individual's entire career (Ball and De Lange 2015; Ng et al. 2005), the school-to-work transition is one of the career aspects most often analyzed (Levels et al. 2014). The smoothness of this transition depends on coping skills, the stability of occupation choice, the time needed to acclimate to the new professional role (responsibility), and, as well, the level of satisfaction with colleagues and labor conditions (Haar et al. 2014).

Transition into adulthood refers to the moment when an individual first enters employment. In addition, it requires being employed for a prolonged period of time in order to meet the obligations resulting from taking on new social roles (Savickas 2013). The simultaneous integration of multiple social roles is a criterion for a successful transition into adulthood (Super 1990). Super identifies six social roles that individuals must perform when they enter adulthood. These are the roles of child, student, worker, leisurite, citizen, and homemaker. The integration of these roles gives people a sense of success in life and results in a positive appraisal of their own career. Career problems are often symptoms of conflicts between these roles (Super et al. 1996). Achieving a balance between many simultaneously-performed roles is particularly important during periods referred as crises or transitions (Levels et al. 2014). 
The first role, namely that of a child, centers on the relationship of individuals with their parents. Before transition into adulthood, this relationship is characterized by the dependence of the child on his/her parents (Arnet 2010). Gradually, their relationship changes and starts to be based on more equal terms. Finally, after becoming an adult, the child's role is to take care of his/her elder parents. Self-efficacy in this role means maintaining equal adult-adult relations and avoiding dependence of the individuals on their parents. According to the EBSCO database, this type of self-efficacy, has not yet been studied. The second role is that of a student, which refers to activities aimed at accumulating knowledge and acquiring skills. This role is performed not only at school but also in other, later forms of education (postgraduate studies, courses, trainings, job shadowing, etc.). The role of student requires an individual's acceptance of the teacher, obedience, and assessments of their academic progress (Bassi et al. 2007; Caprara et al. 2011). Self-efficacy in this role requires dealing with difficult situations, such as learning new material, knowledge testing, etc. (Britner and Pajares 2006). Next, the role of a leisurite is related to the successful organization of an individual's free time in the spheres of time management, profitable use of leisure time, relaxation, and development of interests. Self-efficacy in this domain is determined by the ability to organize leisure in such a way that these goals are achieved (Havitz et al. 2013). The fourth role, that of a citizen, is connected to both political and social public activities. In this case, self-efficacy means that individuals successfully exercise their civil rights and engage in voluntary activities for the benefit of their community (Caprara et al. 2011). The fifth role, that of a worker, is of outmost importance. It is connected with finding and maintaining an occupation that is satisfactory at that stage of life. Self-efficacy in this role is understood as the ability to seek out the most attractive job opportunities, cope with the employer's recruitment requirements, and effectively pass the selection process (Gupta et al. 2013; Lent and Brown 2008). Finally, being a homemaker is a role connected with the organization of an individual's household. The achievement of independence in private life and the establishment of a household, may also be associated with finding a partner and building a satisfactory intimate relationship (Arnet 2010). Most often, studies relate the homemaker role to self-efficacy in parenthood (Spielman and Taubman-Ben-Ari 2009). It is worth to be mentioned that some studies are exclusively focussed on self-efficacy in motherhood (Hudson et al. 2001) or fatherhood (Shorey et al. 2018).

In order to determine the integration of these roles in everyday life, it is still necessary to measure self-efficacy in in a uniform way, hence enabling comparisons and synthesis. Such criteria can only be met by a questionnaire in which self-efficacy is treated as a multidimensional construct. Therefore, in this article we present the process of the creation and validation of such a method. Self-efficacy is a key psychological variable that is discussed in numerous studies as a factor supporting the achievement of goals and the accomplishment of tasks in a given field. It is also very important in the process of transition (Bandura 2001). The utility of the application of the construct of self-efficacy in career assessment and counseling has been widely discussed (Betz 2007; Lent and Brown 2008; Saks et al. 2015).

Self-efficacy is either domain-specific (Bandura 2001; Caprara et al. 2011) or treated as a self-belief pertaining to the entire activity in a person's life (Schwarzer and Jerusalem 1997). There are many studies focused on specific situations, such as playing musical instruments (Clark 2013), solving mathematical tasks (Caprara et al. 2011), looking for a job (Lent et al. 2006), career planning (Falco and Summers 2017; Lent and Brown 2008), or starting a business (Laguna 2013). Existing approaches should be treated as one-sided in describing the phenomenon of self-efficacy. The study of narrow domains of life offers a multidimensional analysis of data on fragments of human activity; however, it is important to view this variable as a generalized perspective on the totality of human life. In the multidimensional understanding of selfefficacy, attempts to determine the function of self-efficacy in certain domains are based on its significance in various other life domains that are more or less similar to the domain analyzed (Guicciardi et al. 2016; Waheed et al. 2015).

In this context, there emerges the need to quantify selfefficacy as a multidimensional construct. Such a measurement should not only distinguish among specific components of the construct, which can be understood as items that are included in the measure of self-efficacy (i.e., aggregate measurement) but should also identify their diverse contributions to the construct (i.e., superordinate measurement; Edwards 2001). The concept of self-efficacy has a rich potential for multidimensional perspectives. These are presented in Table 1. Therefore, the multidimensional perspective relating to various domains of activity will broaden the current approach to this issue and enable a comparative assessment, i.e., establishing in which domains a person perceives themselves as efficient and in which ones they feel helpless.

Adopting Bandura's (2006) approach to analyses of the transition situations, self-efficacy in the fulfillment of obligations arising from assuming and integrating multiple life roles should be analyzed. The level of self-efficacy might be different in each of these. These differences may be realized in difficulties an individual will face in organizing his/her activities and in achieving career satisfaction - and, consequently, in difficulties encountered over his/her entire life. To be able to study this phenomenon in detail and, at the same time, to provide clients with the assistance they need, it is necessary to have an instrument that measures self-efficacy simultaneously across many roles. 
Table 1 Potential dimensions of the multidimensional analysis of the concept of self-efficacy

\begin{tabular}{|c|c|c|}
\hline Dimensions & Contents & Examples \\
\hline Objective & A description of activity or its domain & $\begin{array}{l}\text { Playing musical instruments (Clark 2013), solving math- } \\
\text { ematical tasks (Caprara et al. 2011), self-efficacy in } \\
\text { learning chemistry (Aydin and Uzuntiryaki 2009), } \\
\text { self-efficacy in sport (Feltz et al. 2008), sales } \\
\text { self-efficacy (Gupta et al. 2013), entrepreneurial be- } \\
\text { havior (Chen et al. 2001; Łaguna 2013) }\end{array}$ \\
\hline Subjective & $\begin{array}{l}\text { Who is involved in achieving success; pertains to } \\
\text { individual or collective self-efficacy }\end{array}$ & $\begin{array}{l}\text { independently, as a team, indirectly through someone } \\
\text { (Bandura 2006, Lent et al. 2006; Tasa et al. 2007; } \\
\text { Wang et al. 2010) }\end{array}$ \\
\hline Class of events & $\begin{array}{l}\text { The extent to which the activity is spontaneous or } \\
\text { premeditated }\end{array}$ & $\begin{array}{l}\text { Planned (Bandura 2001), unexpected (Bassi et al. 2007; } \\
\text { Schwarzer et al. 2006) }\end{array}$ \\
\hline The psychologicaldomain & $\begin{array}{l}\text { Concerns particular areas of the functioning of the } \\
\text { psyche }\end{array}$ & Emotions, cognition, behavior (Caprara et al. 2004) \\
\hline Size & $\begin{array}{l}\text { Refers to the magnitude of the obstacle and to the } \\
\text { degree of the sense of being able to cope with it }\end{array}$ & Artistico et al. 2013; Bandura 2006 \\
\hline Strength & $\begin{array}{l}\text { Concerns the degree of certainty of one's } \\
\text { competence }\end{array}$ & Taber and Blankemeyer 2015 \\
\hline Constancy & Resistance to negativefeedback & Bandura 2006; Larson et al. 2014. \\
\hline Generality & The range of situations that self-efficacy concerns & $\begin{array}{l}\text { Specific actions, life domains (Bandura 2011), general } \\
\text { self-efficacy (Schwarzer and Jerusalem 1997) }\end{array}$ \\
\hline
\end{tabular}

\section{Development of the Questionnaire}

\section{Construction of the First Version}

The process of constructing the questionnaire began with a review of the implemented methods used to measure self-efficacy. Among the available methods, one of the most popular is the General Self-Efficacy Scale (GSES) designed by Schwarzer and Jerusalem (1997). Additional methods that serve to measure self-efficacy in specific areas of functioning, such as the High School Chemistry Self-Efficacy Scale (Aydin and Uzuntiryaki 2009), can be applied. However, their scope of generalization is narrow; therefore, there is a clear need to create a new method for a more comprehensive measurement of this essential variable.

The next stage of creating the questionnaire involved generating a list of statements referring to tasks faced by young adults in social roles as identified in Super's (1994) Life-Career Rainbow. Based on 22 interviews with senior-year university and post-graduate students, we identified typical situations and requirements commonly encountered by individuals when they perform particular roles. The data analysis enabled the determination of the specificity of a given situation and the key aspects of behavior in the analogous social role(s). A summary of the proposed descriptions of specific situations and tasks performed in each role, in statements expressing the belief that individuals are able to deal with them effectively, has been derived.

At the current stage, the questionnaire consists of 70 items. It was presented to a group of five expert judges (Ph.D. students in psychology who had recently developed new social roles as part of their transition from education into the job market - two females and three males). The task was to rate the compatibility of the content of each item with the definition of self-efficacy (i.e., content validity). The rating was along a five-point scale: 1 (the item does not match the definition of self-efficacy in the examined area at all) to 5 (the item very closely matches the definition of self-efficacy in the examined area). The mean ratings for individual items ranged from 1.20 to $5.00(M=3.87, S D=1.20$, for the whole pool of statements). The standard deviation for individual items ranged from 0.001 to 0.49 . Inter-rater reliability measured with Krippendorff's alpha $(\alpha)$ was .85 , which shows a high level of agreement in the assessment of the items by individual judges (Hayes and Krippendorff 2007).

The main element of this process was to verify whether the specific situations and statements addressed in the items were actually characteristic for given social roles. In addition, the assessment served as an evaluation of the internal validity of the items considered for inclusion in the constructed questionnaire. Fourteen items were removed, some of them due to low validity scores (below the mean for the entire pool) and the remaining ones because of significant differences in the ratings of the judges (more than two standard deviations for the entire pool).

\section{Study 1: Determining the Factor Structure of the Questionnaire}

The fundamental goals of the first survey were to calculate the discriminatory power indices for the items, to determine the 
factor structure of the scale, and to test its psychometric properties. Due to the considerably high number of areas of young people's activity with respect to the school-to-work transition, we decided to structure them in the survey on the basis of the six major social roles identified by Super (1994). Our exploratory factor analysis has been focused on the most important roles at this stage of professional life.

Method At this stage, factor analysis was performed on the questionnaire that comprised 56 items. A total of 347 graduate university students from Poland were surveyed: 237 females (68.3\%) and 110 males (31.7\%) (Mean age, $M=22.89, S D=$ 2.83 , for the complete set of respondents). The items were rated on a scale from 1 to 6: 1 (definitely disagree), 6 (definitely agree). Adopting such a scale enables the elimination of ambiguous answers (which are not diagnostically useful). The score on a specific subscale is the sum of scores for the items comprising that subscale. The higher the score, the higher the self-efficacy for a given life role.

To measure the criterion validity of the Life Roles SelfEfficacy Scale, we used the following methods: (a) the General Self-Efficacy Scale (GSES) by Schwarzer and Jerusalem (1992); Cronbach's alpha $(\alpha)$ for this sample $=.86$ and (b) Rosenberg's (1989) Self-Esteem Scale; Cronbach's alpha $(\alpha)$ for this sample $=.84$. We also attached a form for collecting participants' personal data to the questionnaire. It included questions about the respondents' gender, year of study, average grade thus far, experience related to each life role (e.g., voting in the last parliamentary elections, going on holiday during the previous summer, home duties, or having a job).

Results Prior to beginning our analyses, we replaced missing values (these represented less than $0.69 \%$ of the full set of data) by using multiple imputation (regression method). Factor analysis was preceded by conducting Bartlett's sphericity test $\left(\chi^{2}=13,537.44, p<.001\right)$ and the Kaiser-MeyerOlkin test of sampling adequacy $(\mathrm{KMO}=.94)$. The values of the two statistics are high and enable the performance of an exploratory factor analysis. We used the method of principal components with promax rotation and Kaiser normalization to select factors. Rotation was chosen as a consequence of the possible correlation of factors and in order to adapt its assumptions to large data sets. When analyzing the relations between self-efficacy in areas such as entrepreneurship and education, Laguna (2013) and Caprara et al. (2011) found moderate and high correlations (respectively from .42 to .93 ) between the identified factors.

In order to test whether the roles identified by Super (1994) can constitute the basis for distinguishing specific selfefficacy areas, we performed an exploratory factor analysis (EFA). This method of analyzing statistical data is recommended by Bandura (2006) as a means of determining the level of homogeneity or complexity of self-efficacy beliefs.
The factor analysis yielded seven factors. The final result of the factor analysis performed with 56 test items is presented in Table 2. Based on the analysis of the scree diagram, the Kaiser criterion, and the assumption that the factor has to explain more than $5 \%$ of the variance (Hair et al. 2010), five factors were selected, which, in total, explained $60.25 \%$ of the variance (the last two factors were discarded, which explained $3.79 \%$ and $2.48 \%$ of the variance, respectively). Parallel analysis and Velicer's MAP test also indicated a 5-factor solution. The factors selected enable an assessment of specific selfefficacy beliefs with regard to basic activities typical for adults.

In accordance with the requirements for newly created tests estimating the time respondents might need to complete the questionnaire, and statistical recommendations that three questions per factor are enough (Hair et al. 2010), we came to the conclusion that there should be three items in each factor of the constructed scale. We decided to include the items that had the highest loadings on their respective factors and to have an equal number of items in each factor. The reliability of the questionnaire was decreased by both increasing and decreasing the number of items in the factors.

The items with factor loadings below .65 were eliminated, as were the items that had similar factor loadings in more than one factor (see Table 2). As a result of this procedure, 35 items were eliminated. We also assessed the discriminatory power of the individual items in the individual subscales, understood as the correlation between the score of an item and that of a given subscale minus the score of that particular item. Items with values $r>.3$ were accepted. Discriminatory power was

Table 2 Factor loadings of the chosen items $(N=347)$

\begin{tabular}{llllll}
\hline Item number & \multicolumn{5}{l}{ Loadings on each factor } \\
\cline { 2 - 6 } & 1 & 2 & 3 & 4 & 5 \\
\hline 37 & .90 & .21 & .26 & .34 & .31 \\
38 & .88 & .25 & .28 & .35 & .37 \\
36 & .87 & .30 & .33 & .24 & .36 \\
44 & .30 & .84 & .20 & .32 & .34 \\
42 & .26 & .86 & .32 & .31 & .30 \\
49 & .25 & .88 & .30 & .35 & .32 \\
26 & .29 & .26 & .82 & .29 & .32 \\
23 & .15 & .30 & .80 & .29 & .26 \\
29 & .46 & .32 & .79 & .30 & .22 \\
51 & .21 & .27 & .26 & .90 & .18 \\
53 & .26 & .28 & .27 & .88 & .10 \\
55 & .22 & .33 & .30 & .86 & .23 \\
3 & .35 & .13 & .30 & .25 & .90 \\
5 & .32 & .24 & .37 & .34 & .89 \\
8 & .35 & .25 & .38 & .41 & .86 \\
\hline
\end{tabular}


insufficient for six statements (below .25 - see Hair et al. 2010); that is why they were discarded in further analyses. After the factor analysis and the discriminatory power analysis, 15 test items remained.

The first factor, Homemaker (explaining $34.77 \%$ of the variance), comprised three items related to self-efficacy in performing tasks and duties of a person responsible for the organization of home and family life. The second factor, Leisurite (explaining $11.18 \%$ of the variance), consisted of items related to an individual's self-efficacy in the domain of recreation as well as planning and organizing their free time in both active and passive forms. The third factor (explaining $10.16 \%$ of the variance) is characterized by an individual's self-efficacy with respect to their planning of a job search, pursuit of chosen professional career, and functioning in the workplace; it is therefore referred to as Worker. The fourth factor, referred to as Citizen (explaining 8.19\% of the variance) pertains to self-efficacy related to performing public, civic, and political duties. The final factor that was selected (explaining $6.78 \%$ of the variance) accounts for self-efficacy as a learner and is referred to as Student. It comprises items related to acquiring knowledge, learning new things, and sitting for exams and tests - all integral elements of the life of a student.

The Life Roles Self-Efficacy Scale (LRSES), as was developed as a result of the exploratory factor analysis (EFA) comprises five subscales that measure the level of self-efficacy in the five social roles outlined above. In accordance with the previously-adopted assumption, each subscale comprises three statements and the final questionnaire consists of 15 items in total.

The reliability of the questionnaire, defined as the internal consistency of the individual subscales, was measured using Cronbach's alpha. The results presented in Table 6 show that the consistency of the scale is acceptable: $\alpha=.88$ for Homemaker, $\alpha=.86$ for Citizen, $\alpha=.85$ for Leisurite, $\alpha=.86$ for Student, and $\alpha=.83$ for Worker. The removal of any of the items did not increase the reliability coefficient in any of the subscales.
We tested convergent and discriminant validity by analyzing the correlations of each scale with the scores on other established instruments measuring related constructs (GSES) and with external criteria, such as average grades, having a job, performing home duties, voting in the last parliamentary election, or going on holiday during the previous summer. The results obtained-moderate correlations between specific self-efficacy beliefs pertaining to individual roles and GSES - confirm that the new scale covers constructs that are to some extent similar to generalized self-efficacy (see Table 3). The moderate correlations values indicate that it is advisable to use both generalized and specific measurements to gain a more comprehensive description of self-efficacy beliefs.

According to Bandura (2011), one of the results of selfefficacy is improved self-esteem. Gupta et al. (2013) also stress the close link between self-efficacy and positive feelings. In our research, we found statistically-significant positive correlations between the new scale that we developed and Rosenberg's (1989) Self-Esteem Scale. This correlation can be explained by the fact that both self-efficacy and selfassessment are judgments about the self (Laguna 2013). However, its moderate level points to the fact that these constructs differ and refer to various areas of self-beliefs.

In order to test external validity, the scores on the individual scales were correlated with objective external criteria (see Table 3). There was a moderate positive correlation between self-efficacy in the role of a student and current average grades $(r=.37, p<.01)$. Self-efficacy in the role of a worker had a moderate positive correlation with having a job $(\eta=.36)$. Selfefficacy in the role of a homemaker had a moderate positive correlation with performing home duties $(\eta=.34)$. Selfefficacy in the role of a leisurite correlated positively $(\eta=.38)$ with going on a holiday during the previous summer. Self-efficacy in the role of a citizen correlated positively with voting in the last parliamentary election $(\eta=.44)$. In all cases, the value of the correlation coefficient was considerably higher than $\eta=.30$. These variables had considerably lower correlations with the remaining subscales, which indicates that

Table 3 Convergent and discriminant validity - correlations of scoreson the subscales of the life roles self-efficacy scale with personality variables and with external criteria

\begin{tabular}{|c|c|c|c|c|c|c|c|}
\hline LRSES & GSES $^{1}$ & SES $^{1}$ & the average of grades ${ }^{a}$ & having a job ${ }^{b}$ & $\begin{array}{l}\text { performing } \\
\text { home duties }\end{array}$ & $\begin{array}{l}\text { a holiday trip during } \\
\text { the last holidays }{ }^{b}\end{array}$ & $\begin{array}{l}\text { participation in the last } \\
\text { parliamentary elections }\end{array}$ \\
\hline Student & $.57 * * *$ & $.48 * * *$ & $.37 * * *$ & .24 & .24 & .25 & .24 \\
\hline Worker & $.51 * * *$ & $.45^{* * *}$ & $.23 * * *$ & .36 & .20 & .30 & .21 \\
\hline Homemaker & $.48 * * *$ & $.36 * * *$ & $.30 * * *$ & .26 & .34 & .21 & .21 \\
\hline Leisurite & $.50 * * *$ & $.37 * * *$ & $.22 * * *$ & .25 & .23 & .38 & .29 \\
\hline Citizen & $.38 * * *$ & $.24 * * *$ & $.25 * * *$ & .22 & .24 & .28 & .44 \\
\hline
\end{tabular}

a Pearson's $r$ correlations, ${ }^{* * *} p<.001$

${ }^{\mathrm{b}} \eta$ correlations; $N=347$ 
the questionnaire has good convergent and discriminant validity.

\section{Study 2 Confirmation of the Factor Structure of the Scale}

In the first survey, a probable factor structure measuring selfefficacy in life roles was identified in the data the data gained from the exploratory factor analysis. Confirmatory evidence in favor of this factor structure was obtained in a subsequent survey, which performed confirmatory factor analysis (CFA) on another sample. The essence of this analysis was to test the goodness-of-fit of the data to various factor structure models.

According to Schwarzer and Jerusalem (1992), selfefficacy is a universal phenomenon. Self-efficacy, understood in this way, means a common belief in people's ability to cope with difficult situations and obstacles related to various areas of human functioning (Schwarzer and Jerusalem 1997). On the basis of this definition, a thesis can be proposed that the phenomenon examined and measured using the scale developed in this study comprises one factor: Model 1. Caprara et al. (2004) assumed that a person perceives hia/her efficacy in terms of three dimensions, namely knowledge, skills, and emotions. According to this approach, the structure of the analyzed construct should comprise three factors consisting of items related to these three areas: Model 2. When examining self-efficacy within a broader domain of activity (e.g., one of the life roles) we can use many specific beliefs that refer to specific tasks and situations within this domain (Larson et al. 2014). In terms of the existence of the five correlated selfefficacy beliefs at the level of individual social roles (Super 1994), such understanding leads to the proposal of the fivefactor model that was developed during the first survey with the use of the exploratory factor analysis (EFA): Model 3. This is consistent with our expectations that the model best fitted to the data would be the solution comprising five moderately-correlated factors.

Method The Life Roles Self-Efficacy Scale (LRSES) was employed. Cronbach's alpha reliability coefficients for the individual subscales were very satisfactory (see Table 6, Study 2). Print copies of the survey were administered to a group of 494 students from three universities in Poland. The respondents' ages ranged between 20 and 28 years, with $M=$
23.55 and $S D=1.40$. The sample was composed of 186 males $(37.7 \%)$ and 308 females (62.3\%). Missing values were not calculated given the large number of participants and analysis conditions.

Results In a confirmatory factor analysis, we verified that the questionnaire had the following three-model factor structure: one-factor (Model 1), three-factor (Model 2), and five-factor (Model 3). The fit indices for the proposed models are presented in Table 4. The one-factor model did not fit the data: the value of $\chi^{2}$ was high and the value of Root mean square error of approximation (RMSEA) exceeded the recommended cutoff (> .10). A high value of $\chi^{2}$ implies high values of the fit indices that are based on it, such as Akaike Information Criterion (AIC), and significantly low values of absolute fit measures: the Goodness of Fit (GFI), the Tucker-Lewis Coefficient (TLC), the Comparative Fit Index (CFI), which means the one-factor model must be rejected (Table 4).

The three-factor model has a slightly better fit than the onefactor model. However, the values measured according to the theory of information (e.g., AIC), RMSEA, and the remaining fit indices failed to reach a satisfactory level (Williams and Holahan 1994), which means this model should be rejected as well. The best fit indices were found in the case of the five-factor model generated in the exploratory factor analysis during the first survey. The proposed distribution of factors after calculating the confirmatory factor analysis fitted the data well in terms of the statistical criteria: $\chi^{2}=217.57, p<.001 ; \chi^{2} / d f=2.72$ (appropriate values for chi-square/degrees of freedom should exceed 1 and should be less than 5) and RMSEA $=.06$ (desired level<.08; Hooper et al. 2008) and SRMR $=.04$ (desired level $<.08$; Hu and Bentler 1999) - and fitted the data sufficiently in terms of the goodness-of-fit indices: $\mathrm{CFI}=.96$; $\mathrm{GFI}=.95$; TLC $=.94$ (Byrne 2010). The obtained values of fit indices were acceptable as they were close to the values obtained in the validation of other methods for measuring psychological variables (see Hooper et al. 2008). Furthermore, when validating their questionnaires, Pignault and Houssemand (2016) and Nilforooshan and Salimi (2016) found that the value of .06 for RMSEA was sufficient to confirm factor structure. As a result of this survey, the five-factor structure of the Life Roles SelfEfficacy Scale was confirmed (See Fig. 1).

In the adopted model, both the five-factor structure and the relations among the factors were confirmed. The loading of each factor was significant at the level of $p<.01$. The factor
Table 4 Goodness-of-fit measures for the models, tested using CFA $(N=494)$

\begin{tabular}{llllllllll}
\hline Models & $\chi^{2}$ & $d f$ & $\chi^{2} / d f$ & RMSEA & SRMR & CFI & GFI & TLC & AIC \\
\hline Model 1 & $1395.38 * * *$ & 90 & 15.50 & .17 & .11 & .60 & .70 & .53 & 1455.39 \\
Model 2 & $1337.92 * * *$ & 88 & 15.20 & .17 & .18 & .65 & .73 & .54 & 1401.93 \\
Model 3 & $217.57 * * *$ & 80 & 2.72 & .06 & .04 & .96 & .95 & .94 & 297.57 \\
\hline
\end{tabular}

$* * * p<.001$ 


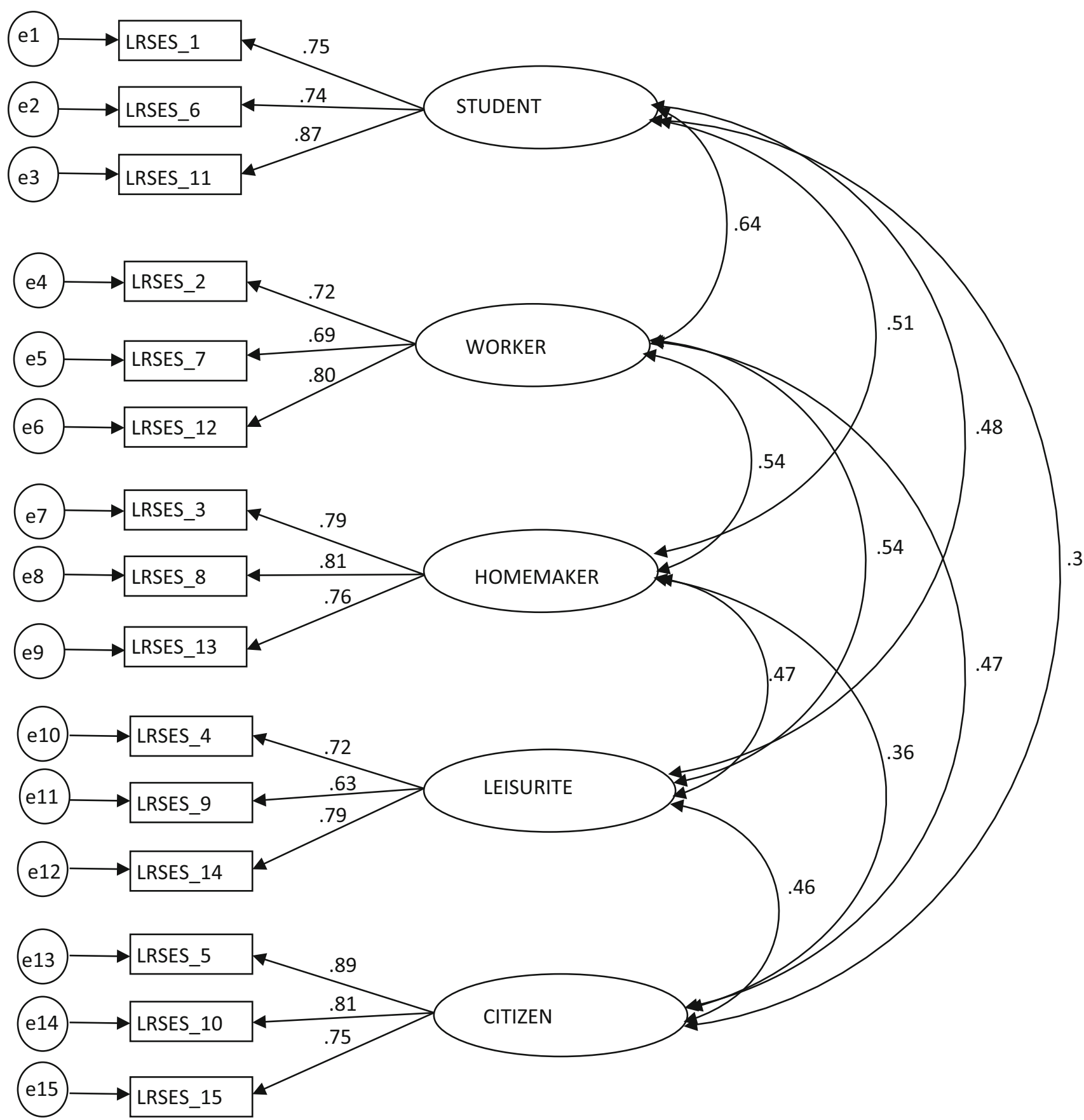

Fig. 1 Model of factor structure of the Life Roles Self-Efficacy Scale (LRSES)

loadings for all of the questionnaire items were acceptable and varied between .72 and .89 , with the factor correlations ranging from .31 to .64 , which is consistent with the previous results (Bandura 2006; Caprara et al. 2011).

\section{Study 3 Measurement Stability}

Apart from reliability, which corresponds to the internal consistency of individual scales, it is useful to determine the reliability index for the entire method, namely the stability of measurement results over time. In order to estimate this parameter, two surveys were conducted on students. The respondents were asked to complete print copies of the questionnaire twice at an interval of two weeks (cf. Bryan et al. 2000).

Method The respondents were first asked to write their code names on the questionnaire. After two weeks, the same respondents were asked to complete the same questionnaire again and to write their code names again so that the answers from the 
same person could be compared. The respondents completed print copies of the Life Roles Self-Efficacy Scale (LRSES) in groups, assisted by an interviewer. In the first stage, the participants were 281 students from Poland. Sixty-six females $(60.55 \%)$ and 43 males $(39.45 \%)$, aged $21-27$ years $(M=$ $22.4, S D=1.96$ ), completed the questionnaire twice.

Comparisons of the results obtained in the first survey by the respondents who did not complete the second survey with the results obtained by those who participated in both surveys revealed a lack of statistically significant differences in the level of self-efficacy.

Results The test-retest method showed high measurement reliability over a period of two weeks (see Table 4). Pearson's $r$ correlations between the specific self-efficacy scores in the two measurements were high, and were as follows for the individual subscales: $r=.92(p<.001)$ for the Student subscale, $r=.84(p<.001)$ for the Worker subscale, $r=.91$ $(p<.001)$ for the Homemaker subscale, $r=.89(p<.001)$ for the Leisurite subscale, $r=.85(p<.001)$ for the Citizen subscale (a summary of means and standard deviations for both measurements is shown in Table 5).

The results of Student's $t$ test for related samples did not reveal any statistically-significant differences between corresponding specific self-efficacy scores in the two measurements. The high stability of the results obtained using the questionnaire over time was confirmed (see Table 5). Moreover, Cronbach's alpha coefficients were acceptable in both measurements (see Table 6).

\section{Validity of the Questionnaire for Various Samples}

The description of the development of the questionnaire is illustrated by the presentation of its descriptive statistics. Table 6 contains descriptive statistics for data collected in 3 studies. The mean scores approximately centered on 13 points, which is slightly higher than the middle of the scale and indicates that the majority of surveyed students had a level of self-efficacy that is higher than the centre of the scale.
Young people often have a level of self-efficacy that is above the average (Wang et al. 2010).

The Kolmogorov-Smirnov test points to a slight deviation of the scores from normal distribution in all of the subscales. The results of estimations of skewness and kurtosis indicate that the distribution of variables is close to normal, with a slight dominance of high scores. In a separate analysis (using the MannWhitney $U$ test) we did not find any statistically-significant differences between males and females for any of the subscales.

The scores on the individual subscales are significantly intercorrelated at a low and medium level (see Table 6), which indicates that the structures are related but not identical. These correlations result from the fact that the same person assumes various roles and acts differently in each of them. Therefore, subjective characteristics (features, strategies, beliefs) will cause a certain degree of similarity in the implementation of different roles. The cohesiveness of the system of self-knowledge and elimination of cognitive dissonance (Festinger 1980) is the reason for similarity of assessments; however, the specificity of domains generates differences. The interaction between these two factors produces moderate correlations. The strongest correlations occur between the roles of a student and an employee, which, from a theoretical point of view, are close to each other and are often treated as a continuation of activity (Savickas 2013; Super 1994). In the area of vocational counseling, the correlation between factors (occupational personality types) also occurs in Holland's (1997) Theory of Career Choice (RIASEC). These correlations reached a level similar to that obtained in our research.

The parameters demonstrated in the individual surveys remained at a similar level, which points to the possibility of replicating the results on samples of the student population. In each survey, we obtained high Cronbach's alpha reliability for the individual subscales.

\section{Discussion}

The purpose of the research described in this article was to develop a new questionnaire measuring self-efficacy based on
Table 5 Summary of means and standard deviations for the results of two measurements performed on the same sample at an interval of 2 weeks $(N=109)$ the life roles self-efficacy scale

\begin{tabular}{|c|c|c|c|c|c|c|c|}
\hline \multirow[t]{2}{*}{ LRSES } & \multicolumn{2}{|c|}{ First measurement } & \multicolumn{2}{|c|}{ Second measurement } & \multirow[t]{2}{*}{$r$} & \multicolumn{2}{|c|}{ Student's $t$ test } \\
\hline & $M$ & $S D$ & $M$ & $S D$ & & $t$ & $p$ \\
\hline Student & 14.38 & 2.50 & 14.04 & 2.51 & $.92 * * *$ & 1.87 & .07 \\
\hline Worker & 14.03 & 2.30 & 13.95 & 2.33 & $.84 * * *$ & .80 & .43 \\
\hline Homemaker & 14.88 & 2.42 & 14.70 & 2.29 & $.91 * * *$ & 1.86 & .07 \\
\hline Leisurite & 11.71 & 3.30 & 11.88 & 3.13 & $.89 * * *$ & 1.80 & .08 \\
\hline Citizen & 12.46 & 2.85 & 12.39 & 2.79 & $.85^{* * *}$ & 1.28 & .20 \\
\hline
\end{tabular}

$* * * p<.001$ 
Table 6 Statistics for the distribution of scores on the life roles self-efficacy scale from all three studies

\begin{tabular}{|c|c|c|c|c|c|c|c|c|c|c|c|c|}
\hline LRSES & $M$ & $S D$ & Min & Max & skewness & kurtosis & K_S $\mathrm{S}^{1}$ & $\alpha$ & 1 & 2 & 3 & 4 \\
\hline \multicolumn{13}{|l|}{ Study $1(\mathrm{~N}=347)$} \\
\hline 1. Student & 13.88 & 2.57 & 5.0 & 18.0 & -.40 & .12 & $.09 * *$ & .86 & & & & \\
\hline 2. Worker & 12.89 & 2.39 & 3.0 & 18.0 & -.36 & .67 & $.09 * *$ & .83 & $.49 * *$ & - & - & - \\
\hline 3. Homemaker & 14.58 & 2.59 & 3.0 & 18.0 & -.50 & -.30 & $.11 * *$ & .88 & $.47 * *$ & $.40 * *$ & - & - \\
\hline 4. Leisurite & 12.44 & 3.21 & 3.0 & 10.0 & -.51 & .07 & $.10 * *$ & .85 & $.46 * *$ & $.42 * *$ & $.36 * *$ & - \\
\hline 5. Citizen & 12.61 & 2.95 & 3.0 & 10.0 & -.44 & .70 & $.08 * *$ & .86 & $.30^{*}$ & $.40 * *$ & $.31 *$ & $.38 * *$ \\
\hline \multicolumn{13}{|l|}{ Study $2(N=494)$} \\
\hline 1. Student & 14.29 & 2.45 & 3.0 & 18.0 & -.56 & .36 & $.08 * *$ & .84 & & & & \\
\hline 2. Worker & 13.55 & 2.40 & 3.0 & 18.0 & -.55 & .75 & $.09 * *$ & .85 & $.64 * *$ & & & \\
\hline 3. Homemaker & 14.60 & 2.44 & 3.0 & 18.0 & -.59 & .45 & $.13^{* *}$ & .87 & $.51 * *$ & $.54 * *$ & & \\
\hline 4. Leisurite & 12.33 & 3.16 & 3.0 & 18.0 & -.45 & .30 & $.10 * *$ & .84 & $.48 * *$ & $.54 * *$ & $.47 * *$ & \\
\hline 5. Citizen & 12.83 & 2.92 & 3.0 & 18.0 & -.33 & .32 & $.09 * *$ & .83 & $.31^{* *}$ & $.47 * *$ & $.36^{* *}$ & $.46^{* *}$ \\
\hline \multicolumn{13}{|c|}{ Study $3.1(N=109)$} \\
\hline 1. Student & 14.38 & 2.50 & 8.0 & 18.0 & -.40 & .30 & $.09^{*}$ & .84 & & & & \\
\hline 2. Worker & 14.03 & 2.30 & 9.0 & 18.0 & -.30 & -.44 & $.10^{*}$ & .86 & $0.64 * *$ & & & \\
\hline 3. Homemaker & 14.88 & 2.42 & 7.0 & 18.0 & -.79 & -.87 & $.17 *$ & .85 & $0.48 * *$ & $0.57 * *$ & & \\
\hline 4. Leisurite & 11.71 & 3.30 & 3.0 & 18.0 & -.33 & .20 & $.08 * *$ & .81 & $0.51 * *$ & $0.52 * *$ & $0.56 * *$ & \\
\hline 5. Citizen & 12.45 & 2.85 & 3.0 & 18.0 & -.40 & -.22 & $.13^{*}$ & .80 & $0.39 * *$ & $0.57 * *$ & $0.42 * *$ & $0.42 * *$ \\
\hline \multicolumn{13}{|c|}{ Study $3.2(N=109)$} \\
\hline 1. Student & 14.04 & 2.51 & 6.0 & 18.0 & .16 & .87 & $.12^{*}$ & .82 & & & & \\
\hline 2. Worker & 13.95 & 2.33 & 7.0 & 18.0 & .07 & -.09 & $.09 *$ & .84 & $.65 * *$ & & & \\
\hline 3. Homemaker & 14.70 & 2.40 & 8.0 & 18.0 & -.26 & -.43 & $.13^{*}$ & .82 & $.45 * *$ & $.50 * *$ & & \\
\hline 4. Leisurite & 11.88 & 3.31 & 4.0 & 17.0 & -.05 & -.61 & $.06^{*}$ & .82 & $.50 * *$ & $.48 * *$ & $.50 * *$ & \\
\hline 5. Citizen & 12.40 & 2.79 & 4.0 & 18.0 & -.15 & .70 & $.15^{*}$ & .76 & $.35^{* *}$ & $.50^{* *}$ & $.35^{* *}$ & $.38^{* *}$ \\
\hline
\end{tabular}

$* * p<.01, * p<.05 ; \mathrm{K} \_\mathrm{S}^{1}-$ Kolmogorov-Smirnov test; The absolute value of a zero-order correlation indicates its effect size (Cohen 1992)

the models that refer to self-knowledge as multilevel structures (Markus and Ruvolo 1989; Porfeli et al. 2011). This questionnaire was meant to assess more general beliefs rather situation-specific ones, but not at the most general level. We therefore intended to extend the current knowledge by designing a questionnaire to measure self-efficacy at the medium level of generality, which refers to social roles performed during people's active professional life (Super 1994). The task was completed successfully; its outcome forms the basis for the 15-item Life Roles Self-Efficacy Scale (LRSES).

The five-factor structure of this new questionnaire, which was derived as a result of the use of exploratory factor analysis, has been positively verified through confirmatory factor analysis of the results obtained on another sample. The existence of five factors in our model was demonstrated to be valid and, at the same time, clearly shows correlations between specific areas of self-efficacy.

The statistical analyses performed on the data obtained in three independent surveys well confirmedthe psychometric properties of the questionnaire. The questionnaire meets the psychometric criteria for questionnaires in scientific research: it has acceptable reliability both for the whole scale and for the individual subscales; further, high stability overtime has been demonstrated with the use of the test-retest method.

When creating the questionnaire, we took care to ensure theoretical validity - the statements retain the sociocognitive nature of Bandura's concept of self-efficacy. The moderate correlations between the specific scales demonstrate the internal validity of the method. The moderate correlations between the Life Roles Self-Efficacy Scale and both the recognized methods of measuring various personality variables (self-esteem, general self-efficacy) and the objective indicators of students' behavior (e.g., having a job, the average grades) also confirm the external validity of the instrument. In order to test its prognostic validity (based on the results obtained) and to draw conclusions about how people will perform in specific life roles in the future, it is necessary to employ the questionnaire in longitudinal research.

Positive correlations of the Life Roles Self-Efficacy Scale with past experiences in performing specific roles and with the results of commonly used and well-established research methods allow this questionnaire to be treated as a valid method of the assessment of self-efficacy in social roles. The scale can be used to test adults' self-efficacy in life roles. The 
identification of areas in which a given individual functions either well or poorly will help that person to prepare for effective functioning in the main life roles that become particularly important in the period of transition from the dependent role of a child or a student to the autonomous roles that require independence as a worker, a homemaker, or a citizen. This will allow the identification of areas in which the person requires support in order to integrate various life domains, which, in turn, will lead to greater satisfaction with their lives and careers.

The scale measuring self-efficacy in specific roles may serve as a method for identifying preferences for particular domains of activity in life. Individuals with low scores may avoid participating in some types of activity because they see themselves as ineffective in a given domain. Identifying such domains and providing support to eliminate doubts as to people's abilities in specific roles could encourage them to become more actively involved in tasks typical for such roles and to persevere if they face difficulties. Further research with the use of the new questionnaire may provide data which might allow a broader assessment of the validity of the scale and its other psychometric properties.

Super (1994) claims that professional activity is one of the basic factors which organizes personality structure, along with other roles such as a homemaker or a leisurite. In his opinion, however, people should perform activities pertaining to many social roles; for example, professional work, family care, spending free time, home activities. Only a synthesis of all of these allows a holistic approach to the organization of personality structure (Guichard and Huteau 2001; Super et al. 1996). This is an extension of the hitherto dominant approach based on the dichotomous division of work-life balance (Haar et al. 2014). Nowadays, the role of a worker also involves constant development of lifelong learning, and it therefore includes the role of a student, which has not been included in any earlier studies on the role of a worker in terms of selfsufficiency (Levels et al. 2014; Super et al. 1996). Existing research in the field of studies on family research has focused on tasks related to family and home life, and has not included any research on the role of a citizen or a leisurite (Haar et al. 2014).

The subjective images of oneself in various roles, situations or social positions are a source of evaluation of an individual's own abilities to perform their own roles and this is reflected in the way self-image is defined (Guichard and Huteau 2001). The key to planning their activities is the belief in their own effectiveness. This concerns not only professional activities (Lent et al. 2006) but also other spheres of life. The measurement of self-efficacy in various roles allows an individual to examine his/her ability to maintain a balance between personal and professional environments. Maintaining this balance is linked to the belief that these roles are effective. The relationship between the roles of a worker and a homemaker, as well as an employee and a leisurite, which are described in the literature in terms of work-life balance, is of key importance. This is a central aspect of career adaptability; it is related to the ability of an individual to self-reflect, decide for oneself, plan in the long term and search for and achieve new positions in his/her career (Savickas 2013). Blustein (1997) also pointed out the need for such a comprehensive approach. In his opinion, the Life-Career Rainbow and adaptability models may be instrumental in developing a context-rich perspective of career exploration in the theory, research, and practice agendas of the twenty-first century.

The presented analyses confirms the usefulness of the validated questionnaire. The indicators fully meet the standard psychometric requirements. In terms of content, we can confidently state that the simultaneous measurement of selfefficacy in many roles enables a more comprehensive view of the situation of the individual in the labor market. Individual roles are linked but not identical, which shows the richness of possible interactions among them. Rożnowski and Kot $(2016,2018)$ stress the importance of self-efficacy in the role of a leisurite, which helps graduates to embark on employment. They also emphasize the transfer of self-efficacy into new roles based on beliefs that arise from confidence in known roles.

The questionnaire is suitable for scientific research, but it can also be used in advisory practice to assess how people deal with problems arising in different spheres of life. According to Savickas (2012), unstable labor markets and precarious careers can set workers adrift as they try to plan their professional future and shape their identities. Nowadays, career transition requires deeper self-knowledge and more effort than ever before. Career advisors and researchers are now formulating new constructs to help clients to plan career changes over their lifespan without losing a sense of self or social identity (Guichard and Huteau 2001). Self-efficacy in various social roles is one of these constructs (Lent et al. 2006; Rożnowski and Kot 2018).

\section{Limitations and Future Directions}

The present studies have some limitations that should be considered before planning further similar research. It should be remembered that the validity of the questionnaire was based solely on data obtained from a group of university graduates, which represents only one of the many possible paths of youth transition to the labor market. Further studies are needed to check the utility this of the questionnaire both in cases of other paths wihin the first transition to the labor market (for example, graduates of vocational school, high school, and primary school) as well as transitions during other stages of one's career path. 
In subsequent studies, it may be beneficial to check whether the results of the test differ significantly due to gender or socioeconomic conditions of the respondents. Moreover, it would be useful to prepare different language versions of the questionnaire to check for cross-cultural similarities and differences, for example, in more collectivist and individualistic countries. Examining people at different stages of their carrers could also provide valuable information.

Funding The study was supported by, based on the decision no.

Data Availability The datasets generated during and/or analysed during the current study are available from the corresponding author on reasonable request.

\section{Compliance with Ethical Standards}

Conflict of Interest On behalf of all authors, the corresponding author states that they have no conflict of interest.

Ethical Approval All procedures performed in studies involving human participants were in accordance with the ethical standards of the institutional and/or national research committee and with the 1964 Helsinki Declaration and its later amendments or comparable ethical standards.

This article does not contain any studies with animals performed by any of the authors.

Informed Consent Informed consent was obtained from all individual participants included in the study.

Open Access This article is licensed under a Creative Commons Attribution 4.0 International License, which permits use, sharing, adaptation, distribution and reproduction in any medium or format, as long as you give appropriate credit to the original author(s) and the source, provide a link to the Creative Commons licence, and indicate if changes were made. The images or other third party material in this article are included in the article's Creative Commons licence, unless indicated otherwise in a credit line to the material. If material is not included in the article's Creative Commons licence and your intended use is not permitted by statutory regulation or exceeds the permitted use, you will need to obtain permission directly from the copyright holder. To view a copy of this licence, visit http://creativecommons.org/licenses/by/4.0/

\section{References}

Arnet, J. J. (2010). Adolescence and emerging adulthood. Boston: Prentice Hall.

Artistico, D., Pinto, A. M., Douek, J., Black, J., \& Pezzuti, L. (2013). The value of removing daily obstacles via everyday problem-solving theory: Developing an applied novel procedure to increase selfefficacy for exercise. Frontiers in Psychology, 4(20), 2-9. https:// doi.org/10.3389/fpsyg.2013.00020.

Aydin, Y. C., \& Uzuntiryaki, E. (2009). Development and psychometric evaluation of the high school chemistry self-efficacy scale. Educational and Psychological Measurement, 69, 868-880. https://doi.org/10.1177/0013164409332213.

Ball, M. P., \& De Lange, A. H. (2015). From flexibility human resource management to employee engagement and perceived job performance across the lifespan: A multisample study. Journal of
Occupational and Organizational Psychology, 88, 126-154. https://doi.org/10.1111/joop.12082.

Bandura, A. (2001). Social cognitive theory: An agentic perspective. Annual Review of Psychology, 52, 1-26. https://doi.org/10.1146/ annurev.psych.52.1.1.

Bandura, A. (2006). Guide for constructing self-efficacy scales. In F. Pajares \& T. Urdan (Eds.), Self-efficacy beliefs of adolescents (pp. 307-337). Greenwich: Information Age Publishing.

Bandura, A. (2011). Social cognitive theory. In P. A. M. Lange, A. W. Kruglanski, \& E. T. Higgins (Eds.), Handbook of social psychological theories (pp. 349-373). London: Sage.

Bassi, M., Steca, P., Fave, A., \& Caprara, G. V. (2007). Academic selfefficacy beliefs and quality of experience in learning. Journal of Youth and Adolescence, 36, 301-312. https://doi.org/10.1007/ s10964-006-9069-y.

Betz, N. E. (2007). Career self-efficacy: Exemplary recent research and emerging directions. Journal of Career Assessment, 15(4), 403422. https://doi.org/10.1177/1069072707305759.

Blustein, D. L. (1997). The role of work in adolescent development. The Career Development Quarterly, 45(4), 381-389. https://doi.org/10. 1002/j.2161-0045.1997.tb00541.x.

Briscoe, J. P., Chudzikowski, K., \& Unite, J. (2012). Career transitions: Windows into the career experience in 11 country contexts. In J. P. Briscoe, D. Hall, \& M. Mayrhofer (Eds.), Careers around the world: Individual and contextual perspectives (pp. 88-117). London: Routledge.

Britner, S. L., \& Pajares, F. (2006). Sources of science self-efficacy beliefs of middle school students. Journal of Research in Science Teaching, 43(5), 485-499. https://doi.org/10.1002/tea.20131.

Bryan, S., Gold, L., Sheldon, R., \& Buxton, M. (2000). Preference measurement using conjoint methods: An empirical investigation of reliability. Health Economics, 9(5), 385-395. https://doi.org/10.1002/ 1099-1050(200007)9:5<385::aid-hec533>3.0.co;2-w.

Byrne, B. M. (2010). Structural equation modeling with AMOS: Basic concepts, applications, and programming. London: Routledge Academic.

Caprara, G. V., Barbaranelli, C., Pastorelli, C., \& Cervone, D. (2004). The contribution of self-efficacy beliefs to psychosocial outcomes in adolescence: Predicting beyond global dispositional tendencies. Personality and Individual Differences, 37, 751-763. https://doi. org/10.1016/j.paid.2003.11.003.

Caprara, G. V., Vecchione, M., Alessandri, G., Gerbino, M., \& Barbaranelli, C. (2011). The contribution of personality traits and self-efficacy beliefs to academic achievement: A longitudinal study. The British Psychological Society, 81, 78-96. https://doi.org/10. 1348/2044-8279.002004.

Chen, G., Gully, S. M., \& Eden, D. (2001). Validation of a new general self-efficacy scale. Organizational Research Methods, 4(1), 62-68. https://doi.org/10.1177/109442810141004.

Clark, J. C. (2013). A qualitative exploration of higher self-efficacy string students preparing for a competition. International Journal of Music Education, 31(1), 4-14. https://doi.org/10.1177/ 0255761411431393.

Cohen, J. (1992). A power primer. Psychological Bulletin, 112(1), 155 159 0033-2909/92/S3-0.

Edwards, J. R. (2001). Multidimensional constructs in organizational research: An integrative analytical framework. Organizational Research Methods, 4(2), 144-192. https://doi.org/10.1177/ 109442810142004.

Falco, L. D., \& Summers, J. J. (2017). Improving career decision selfefficacy and STEM self-efficacy in high school girls. Journal of Career Development, 089484531772165. https://doi.org/10.1177/ 0894845317721651.

Feltz, D. L., Short, S. E., \& Sullivan, P. J. (2008). Self-efficacy in sport. Champaign: Human Kinetics. 
Festinger, L. (1980). Retrospections on social psychology. Oxford: Oxford University Press.

Guicciardi, M., Fadda, D., \& Delitala, L. (2016). A new multidimensional scale for measuring self- efficacy beliefs in volleyball. International Journal of Sport Psychology, 47, 13-25. https://doi.org/10.7352/ IJSP2016.47.013.

Guichard, J., \& Huteau, M. (2001). Psychologie de l'orientation. Paris: Dunod.

Gupta, N., Ganster, D. C., \& Kepes, S. (2013). Assessing the validity of sales self-efficacy: A cautionary tale. Journal of Applied Psychology, 98(4), 690-700. https://doi.org/10.1037/a0032232.

Haar, J. M., Russo, M., Sune, A., \& Ollier-Malaterre, A. (2014). Outcomes of work-life balance on job satisfaction, life satisfaction and mental health: A study across seven cultures. Journal of Vocational Behavior, 85(3), 361-373. https://doi.org/10.1016/j. jvb.2014.08.01.

Hair, J. F., Black, W. C., Babin, B. J., \& Anderson, R. E. (2010). Multivariate Data Analysis. New York: Prentice Hall.

Havitz, M. E., Kaczynski, A. T., \& Mannell, R. C. (2013). Exploring relationships between physical activity, leisure involvement, selfefficacy, and motivation via participant segmentation. Leisure Sciences: An Interdisciplinary Journal, 35(1), 45-62. https://doi. org/10.1080/01490400.2013.739890.

Hayes, A. F., \& Krippendorff, K. (2007). Answering the call for a standard reliability measure for coding data. Communication Methods and Measures, 1, 77-89. https://doi.org/10.1080/ 19312450709336664.

Holland, J. L. (1997). Making vocational choices: A theory of vocational personalities and work environments. Odessa: Psychological Assessment Resources.

Hooper, D., Coughlan, J., \& Mullen, M. (2008). Structural equation Modelling: Guidelines for determining model fit. Journal of Business Research Methods, 6(1), 53-60. https://doi.org/10.21427/ D7CF7R.

Hu, L., \& Bentler, P. M. (1999). Cutoff criteria for fit indexes in covariance structure analysis: Conventional criteria versus new alternatives. Structural Equation Modeling, 6, 1-55. https://doi.org/10. 1080/10705519909540118.

Hudson, D. B., Elek, S. E., \& Feleck, M. O. (2001). First-time mothers' and fathers' transition to parenthood: Infant care self-efficacy, parenting satisfaction, and infant sex. Issues in Comprehensive Pediatric Nursing, 24(1), 31-43. https://doi.org/10.1080/ 014608601300035580

Łaguna, M. (2013). Self-efficacy, self-esteem, and entrepreneurship among the unemployed. Journal of Applied Social Psychology, 43, 253-262. https://doi.org/10.1111/j.1559-1816.2012.00994.x.

Larson, L. M., Stephen, A., Bonitz, V. S., \& Wu, T.-F. (2014). Predicting science achievement in India: Role of gender, self-efficacy, interests, and effort. Journal of Career Assessment, 22(1), 89-101. https://doi. org/10.1177/1069072713487975.

Lent, R. W., \& Brown, S. D. (2008). Social cognitive career theory and subjective well-being in the context of work. Journal of Career Assessment, 16(1), 6-21. https://doi.org/10.1177/ 1069072707305769.

Lent, R. W., Schmidt, J., \& Schmidt, L. (2006). Collective efficacy beliefs in student work teams: Relation to self-efficacy, team cohesion, and team performance. Journal of Vocational Behavior, 68(1), 7384. https://doi.org/10.1016/j.jvb.2005.04.001.

Levels, M., Van der Velden, R., \& Di Stasio, V. (2014). From school to fitting work: How education-to-job matching of European school leavers is related to educational system characteristics. Acta Sociologica, 57(4), 341-361. https://doi.org/10.1177/ 0001699314552807.

Markus, H., \& Ruvolo, A. (1989). Possible selves: Personalized representations of goals. In L. A. Pervin (Ed.), Goal concepts in personality and social psychology (pp. 211-241). Hillsdale: Erlbaum.
Ng, T. W., Eby, L. T., Sorensen, K. L., \& Feldman, D. C. (2005). Predictors of objective and subjective career success: A meta-analysis. Personnel Psychology, 58(2), 367-408. https://doi.org/10. 1111/j.1744-6570.2005.00515.x.

Nilforooshan, P., \& Salimi, S. (2016). Career adaptability as a mediator between personality and career engagement. Journal of Vocational Behavior, 94, 1-10. https://doi.org/10.1016/j.jvb.2016.02.010.

Pignault, A., \& Houssemand, C. (2016). Construction and initial validation of the work context inventory. Journal of Vocational Behavior, 92, 1-11. https://doi.org/10.1016/j.jvb.2015.11.006.

Porfeli, E., Lee, B., Vondracek, F., \& Weigold, I. (2011). A multidimensional measure of vocational identity status. Journal of Adolescence, 34(5), 853-871. https://doi.org/10.1016/j. adolescence.2011.02.001.

Rosenberg, M. (1989). Society and adolescent self-image. Revised edition. Middletown: Wesleyan University Press.

Rożnowski, B., \& Kot, P. (2016). Przenoszenie przekonania o własnej skuteczności w nową rolę życiową: model moderacyjny i mediacyjny. [Projecting self-efficacy beliefs to a new role in life: mediation model]. Czasopismo Psychologiczne. [Psychological Journal], 22(2), 205-218.

Rożnowski, B., Kot, P. (2018). Poziom przekonania o własnej skuteczności, a posiadanie zatrudnienia na różnych etapach tranzycji. [Self-efficacy at various stages of the transition from education to work]. Czasopismo Psychologiczne. [Psychological Journal], 24(1), 133-142.

Saks, A. M., Zikic, J., \& Koen, J. (2015). Job search self-efficacy: Reconceptualizing the construct and its measurement. Journal of Vocational Behavior, 86, 104-114. https://doi.org/10.1016/j.jvb. 2014.11.007.

Savickas, M. L. (2012). Life design: A paradigm for career intervention in the $21^{\text {st }}$ century. Journal of Counseling and Development, 90, 13 19.

Savickas, M. L. (2013). Career construction theory and practice. In R. W. Lent \& S. D. Brown (Eds.), Career development and counseling: Putting theory and research to work (pp. 147-183). Hoboken: John Wiley and Sons.

Schlossberg, N. K. (1996). A model of worklife tranistions. In R. Feller \& G. Walz (Eds.), Career transitions in turrbulent time (pp. 93-104). Greensboro: ERIC Publication.

Schwarzer, R., \& Jerusalem, M. (1992). Self-efficacy as a resource factor in stress appraisal processes. In R. Schwarzer (Ed.), Self-efficacy. Thought control of action (pp. 25-63). Washington: Hemisphere.

Schwarzer, R., \& Jerusalem, M. (1997). Generalized self-efficacy scale. In J. Weinman, S. Wright, \& M. Johnston (Eds.), Measures in health psychology: A user's portfolio (pp. 35-38). Windsor: NFERNelson.

Schwarzer, R., Luszczynska, A., Boehmer, S., Taubert, S. \& Knoll, N. (2006). Changes in finding benefit after cancer surgery and the prediction of well-being one year later. Social Science \& Medicine, 63(6), 1614-1624. https://doi.org/10.1016/j.socscimed.2006.04. 004.

Shorey, S., Ng, Y., Siew, A. L., Yoong, J., \& Mörelius, E. (2018). Effectiveness of a technology-based supportive educational parenting program on parental outcomes in Singapore: Protocol for a randomized controlled trial. JMIR Research Protocols, 7(1), e4. https:// doi.org/10.2196/resprot.8062.

Spielman, V., \& Taubman-Ben-Ari, O. (2009). Parental self-efficacy and stress-related growth in the transition to parenthood: A comparison between parents of pre- and full-term babies. Health \& Social Work, 34(3), 201-212. https://doi.org/10.1093/hsw/34.3.201.

Super, D. E. (1990). A life-span, life-space approach to career development. In D. Brown \& L. Brooks (Eds.), Career choice and development (pp. 197-261). San Francisco: Jossey-Bass. 
Super, D. E. (1994). A life-span, life-space perspective on convergence. In M. L. Savickas \& W. W. Lent (Eds.), Convergence in career development theories (pp. 63-74). Palo Alto: CPP BOOKS.

Super, D. E., Savickas, M. L., \& Super, C. M. (1996). The life-span, lifespace approach to careers. In D. Brown \& L. Brooks (Eds.), Career choice and development (pp. 121-178). San Francisco: Jossey-Bass.

Taber, B. J., \& Blankemeyer, M. (2015). Future work self and career. Adaptability in the prediction of proactive career behaviors. Journal of Vocational Behavior, 86, 20-27. https://doi.org/10.1016/j.jvb. 2014.10.005.

Tasa, K., Taggar, S., \& Seijts, G. H. (2007). The development of collective efficacy in teams: A multilevel and longitudinal perspective. Journal of Applied Psychology, 92(1), 17-27. https://doi.org/10. 1037/0021-9010.92.1.17.

Waheed, M., Kaur, K., Ain, N., \& Sanni, S. A. (2015). Emotional attachment and. Multidimensional self-efficacy: Extension of innovation diffusion theory in the context of eBook reader. Behaviour \& Information Technology, 34, 1147-1159. https://doi.org/10.1080/ 0144929X.2015.1004648.

Wang, J., Zhang, J., \& Shao, J. (2010). Group training on the improvement of college students' career decision-making self-efficacy. Health, 6, 551-556. https://doi.org/10.4236/health.2010.26082.

Williams, L. J., \& Holahan, P. J. (1994). Parsimony-based indices for multiple-indicator models: Do they work? Structural Equation Modeling, 1(2), 161-189. https://doi.org/10.1080/ 10705519409539970 .

Publisher's Note Springer Nature remains neutral with regard to jurisdictional claims in published maps and institutional affiliations. 